\title{
Massive amyloidosis of mediastinal lymph nodes in a patient with multiple myeloma
}

\author{
M MELATO, G ANTONUTTO, G FALCONIERI, R MANCONI \\ From the Istituto di Anatomia e Istologia Patologica dell'Università di Trieste, Trieste, Italy
}

Intrathoracic amyloidosis affecting the lungs or mediastinum, or both, is a very rare condition. Only single cases have been studied clinically and radiographically and relatively little attention has been given to its pathological features. $^{1-3}$

\section{Case report}

A 66-year-old woman suffering from recurrent episodes of bronchopneumonia was admitted to the hospital in January 1979 with a two-year history of mild intermittent fever, weight loss, anorexia, and weakness. The family history was unremarkable. Physical examination showed only a slight enlargement of inguinal and laterocervical lymph nodes.

At the first admission laboratory data showed anaemia (Hb $9.8 \mathrm{~g} / \mathrm{dl}$, red blood cells $4.1 \times 10^{12} / 1$, mean corpuscular volume $72 \mu^{3}$, packed cell volume $0 \cdot 29$ ). The leucocyte count was $5.6 \times 10^{9} / 1$, with an unremarkable differential count, and the platelet count was $37 \times 10 \%$. The blood iron concentration was $30 \mu \mathrm{g} / \mathrm{dl}$. The ESR was $82 \mathrm{~mm}$ in the first hour. The total protein concentration was $5.6 \mathrm{~g} / \mathrm{dl}$. Electrophoresis showed an albumin percentage of $40.2 \%$, $\alpha_{1} 6.4 \%, \alpha_{2} 14.5 \%, \beta 11.3 \%, \gamma 27.5 \%$. The IgG concentration was $1800 \mathrm{mg} / \mathrm{dl}$, IgA $210 \mathrm{mg} / \mathrm{dl}$, and IgM $110 \mathrm{mg} /$ dl. Examination for Bence-Jones protein was positive for the $\lambda$ type. Bone aspiration showed complete replacement of marrow by large numbers of plasma cells. The diagnosis was micromolecular $\lambda$ myeloma.

A chest radiograph showed an enlarged right hilar profile, likely to be due to lymph-node tumour (fig 1). Tomography showed a homogeneous opacity below the tracheobronchial angle deforming the middle-lobe bronchus. Mediastinoscopy was not performed owing to technical difficulties.

The patient started a six-week-cycle course of chemotherapy with an alkylating drug (melphalan) and fluorocortisone and after remission was discharged. Weakness and anorexia, however, were always present until February 1980. In March 1980 pain and fever with oedema of the lower extremities appeared and admission was again required. Laboratory data were similar to those at the first admission. A chest radiograph showed a pleural effusion on the right side. Despite appropriate treatment the patient died in April 1980.

Necropsy showed a large mediastinal mass, which was

Address for reprint requests: Dr M Melato, Istituto di Anatomia e Istologia Patologica, Ospedale Maggiore, Via Pietà 2/2, I-34125 Trieste, Italy.

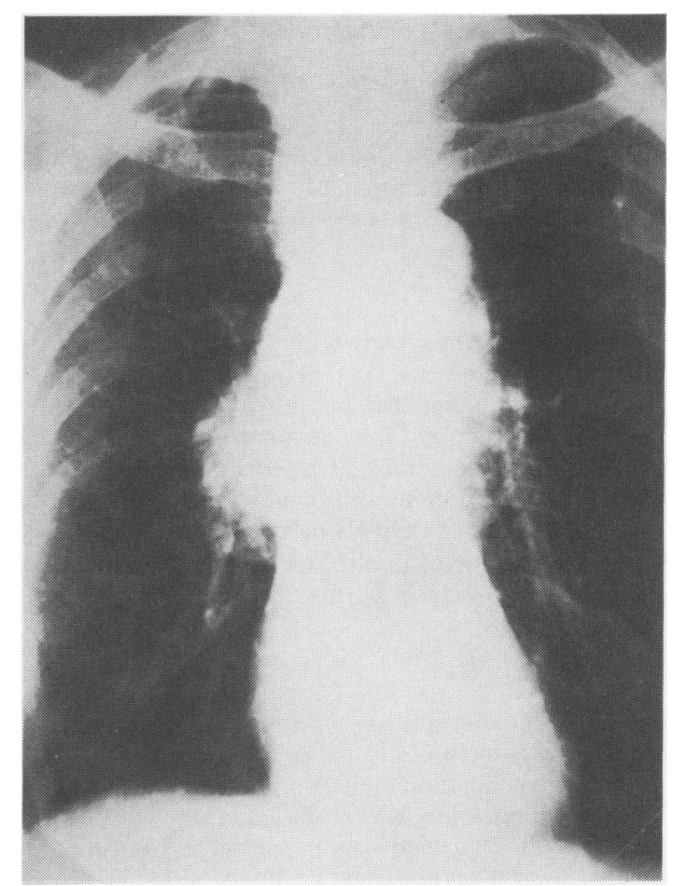

Fig 1 Chest radiograph showing enlargement of right hilar profile.

compressing adjacent structures and adherent to the vertebral column. The oesophagus and trachea were compressed and displaced towards the left, and the right lung was severely atelectatic.

The tumour mass appeared to arise from mediastinal lymph nodes and had an irregular oval shape. It was $10 \mathrm{~cm}$ in length and weighed $330 \mathrm{~g}$; the external surface appeared homogeneous, yellow, and translucent. The cut surface was similar to the external one and showed neither haemorrhages nor necrosis (fig 2).

Histological examination of bone marrow confirmed the diagnosis of plasmocytoma. The mediastinal tumour appeared histologically to be entirely composed of eosinophilic glass-like and homogeneous material in a lymph-node structure, as shown by the presence of small clusters of lymphoid tissue and dark granular areas corresponding to anthracotic deposits. Isolated plasma cells were present but no myelomatous tissue was seen. A search for amyloid substance by Congo red staining showed all organs 


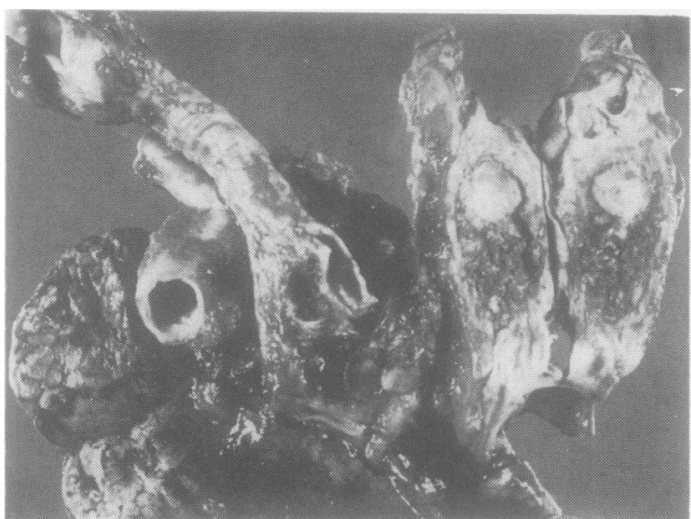

Fig 2 Postmortem specimen, posterior view: the right lung has been removed and the tumour (on the right) has been cut open.

to be severely affected with both vascular and interstitial morphological patterns of deposition. The amyloid deposits of the mediastinal tumour as well as those from the other sites examined were recognised by histochemical methods to be of the immuno type of amyloid ${ }^{4}$ as they were positive for tryptophan and tyrosine stains and autofluorescence under ultraviolet light. Amyloid deposits and amyloid tumour proved also to be resistant to trypsin digestion $^{5}$ and potassium permanganate reaction. ${ }^{6}$

\section{Discussion}

Studies of the distribution of intrathoracic amyloidosis show that amyloid is only exceptionally confined to the lungs ${ }^{7}$ and that amyloid tumours are uncommon entities. Hilar lymph nodes are seldom affected.

The present case seems to be rather exceptional from both clinical and pathological points of view. Besides the singular size of the amyloid mass, the patient had severe systemic amyloidosis and was affected by multiple myeloma. Non-myelomatous conditions are reported as a cause of pseudotumoral amyloid enlargement of mediastinal lymph nodes. ${ }^{23}$ The same kind of mediastinal mass may be observed in the course of systemic amyloidosis, both primary and secondary. ${ }^{18}$ Such amyloid tumours are probably more frequent than expected in a general population. ${ }^{1}$
The pathogenesis of the process occurring in our case and in previously published cases is unknown, as is the? pathogenesis of amyloid disease itself. The light chains of immunoglobulins are probably important in primary and myeloma-associated amyloidosis (AL type-that is amyloid light chains). ${ }^{9}$

From our experience we would emphasise the impor tance of pathological examination for assessing the reap nature of a mediastinal mass.

We thank Professor L Dalla Palma, head of the Istituto d $\overrightarrow{\vec{\omega}}$ Radiologia of the University of Trieste, and his assistan? Dr GB Bellis for having kindly provided the $x$-ray films $\overrightarrow{\vec{x}}$ We thank also Mrs Maria Pegan for her helpful technicad assistance.

\section{References}

${ }^{1}$ Kidd CR, Fred HL, Natelson EA. Bilateral hilă adenopathy in amyloidosis. $N$ Engl $J$ Med 197促
290:972.

${ }^{2}$ Wilson SR, Sanders DE, Delarue NC. Intrathoracic mane ifestations of amyloid disease. Radiology 197£ 120:283-9.

${ }^{3}$ Osnoss KL, Harrell DD. Isolated mediastinal mass id primary amyloidosis. Chest 1980;78:786-8.

${ }^{4}$ Pearse AGE, Ewen SWB, Polak JM. The genesis apudamyloid in endocrine polypeptide tumors: his tochemical distinction from immunamyloid. Virchow Arch abt B (Cell Pathol) 1972;10:93-107.

5 Romhànyi G. Differences in ultrastructural organisatio $\overrightarrow{\bar{B}}$ of amyloid as revealed by sensitivity or resistance te induced proteolysis. Virchows Arch abt A (Pathot Anat) 1972;357:29-52.

${ }^{6}$ Wright JR, Calkins E, Humphrey RL. Potassium per manganate reaction in amyloidosis. A histologio method to assist in differentiating forms of this dis ease. Lab Invest 1977;36:274-81.

${ }^{7}$ Melato M, Bianchi C. Pulmonary amyloidosis wit unusual pathological features. Morphol Embryof. (Bucur) 1978;24:133-5.

${ }^{8}$ Desai RA, Mahajan VK, Benjamin S, Van Ordstrang HS, Cordasco EM. Pulmonary amyloidoma and hilat adenopathy. Chest 1979;76:170-3.

${ }^{9}$ Glenner GG. Amyloid deposits and amyloidosis. $N$ En J Med 1980;302:1283-343. 